\title{
Analisa Hubungan Pola Komunikasi Dan Tingkat Keaktifan Pimpinan Terhadap Loyalitas Anggota Pada Komunitas Fotografi Urban Explore Bekasi (Leadership)
}

\author{
Faqihar Risyan \\ Universitas Bina Sarana Informatika \\ email: faqihar.fqr@bsi.ac.id
}
Cara Sitasi: Risyan, F. (2019). Analisa Hubungan Pola Komunikasi Dan Tingkat Keaktifan Pimpinan Terhadap Loyalitas Anggota Pada Komunitas Fotografi Urban Explore Bekasi ( Leadership ). Jurnal Komunikasi, 10(1), 64-68.

\begin{abstract}
Abstact- This research aims to know the influence of communication patterns and levels of liveliness a leader against the loyalty member in urbex People community beksi region. This research was categorized in the research survey, with research instrumentin the form of a questionnaire. The research is the study of the population by the number of respondents 108 member of urbex people community Bekasi region. metode of research used in this study is a qualitative method, using the approach of Phenomenology. Results of the study found that: (1) a leader of communication patterns of a positive effect against the loyalty member. (2) the level of positive against the influential leader of the liveliness of the loyalty member. (3) the communication pattern and tiers in the influential leader of the simultaneous activity against the loyalty member. It could be said the number of members was strongly influenced by the patterns of communication and levels of liveliness leader itself.
\end{abstract}

KeyWords : Communication Pattern, level of liveliness, and loyality

\section{PENDAHULUAN}

Urbex People adalah sebuah komunitas urban photography yang bergerak di sosial media Instagram. Kata "URBEX" sendiri di ambil dari kata "URBAN EXPLORATION". Komunitas ini didirikan oleh Dhery pada tanggal 25 september 2013. Hingga sampai sekarang berkembang menjadi komunitas yang solid yang terbagi dari beberapa region yang tersebar di setiap kota di Indonesia. UrbexPeople sendiri mempunyai ciri khas dari segi foto. Mereka biasanya memotret reruntuhan bangunan atau gedung yang sudah ditinggalkan. Dan urbexpeople sendiri dibentuk untuk mewadahi pengalaman seputar urban exploration Photography"

Di setiap region urbexpeople memiliki leader masing-masing untuk mengkoordinir setiap member nya. Dan masing-masing leader memliki karakter yang berbeda di setiap regional. Penulis mengangkat satu konteks penelitian sesuai dengan domisili nya, yaitu bekasi. Maka dari itu penulis mengangkat satu komunitas urbex people regional bekasi.
Menurut dhery, leader dari urbex people se Indonesia, komunitas ini didirikan atas dasar mengumpulkan orang-orang yang memiliki hoby fotografi, khususnya street photography. Karakteristik foto ini biasanya mengambil objek gedung-gedung tua, bangunan tua, jalanan, atau sesuatu yang sudah ditinggalkan oleh penghuni nya. Bahkan mereka tidak segan-segan untuk naik ke lantai gedung tertinggi hanya untuk mengambil foto landscape satu kota tertentu. Dan tentu nya hasil foto masuk ke meja editing sebelum di posting ke sosial media. Kualitas foto, kekompakan member dan konsistenitas member hal tersebut di pengaruhi oleh karakter seorang leader. Atau bahkan naik turun nya jumlah member dipengaruhi oleh karakter seorang leader.

Loyalitas pada dasar nya suatu kesetian anggota kepada atasan atau pemimpin nya sehingga setiap anggota nya dapat memberikan kontribusi kepada sebuah organisasi, dalam hal ini sebuah komunitas. Loyalitas member sangat berpengaruh terhadap kemajuan suatu komunitas, ketika banyak member yang tidak loyal terhadap komunitas, maka banyak member yang pasif, tidak memberikan sebuah 
kontribusi bahkan keluar dari kemunitas itu. Apabila permasalahan tersebut tidak dapat di atasi dengan baik, maka tujuan dari sebuah organisasi atau komunitas tersebut akan terhambat. Untuk itu peranan seorang leader atau founder sangat di butuhkan untuk membuat member tetap loyal terhadap komunitas ini.

Untuk membatasi masalah yang muncul satu komunitas fotografi yang berdomisili di wilayah bekasi, yakni "Urban Explore People regional Bekasi”. komunitas ini hanya sebagian kecil dari urbex people pusat. Bagian-bagian tersebut disebut region, tujuan nya untuk mengkontrol membermember sesuai domisili nya. Komunitas ini di buat oleh seorang mahasiswa dari kampus ternama di Bekasi, dan seluruh anggota nya memiliki hobby yang sama, yaitu fotografi. Sebelum nya para anggota memiliki harapan adanya wadah untuk meng explore karya foto nya ke media sosial yang sifat nya komersial. Maka dari itu banyak dari mereka yang bergabung ke komunitas ini untuk pencapaian tersebut. "Komunikasi adalah pertukaran pesan verbal maupun nonverbal antara si pengirim dengan si penerima pesan untuk mengubah tingkah laku.” (Muhammad, 2009).

Sedangkan definisi dari Ilmu komunikasi menurut Drs. A.M. Hoeta Soehoet adalah ilmu yang mempelajari usaha manusiadalam menyampaik an isi pernyataannya kepada manusia lain. Kajian ilmu komunikasi yang kita bahas adalah menyampaikan IP kepada manusia lain, karena hanya mahluk yang punya akal danbudi saja yang mampu memahami hasil penggunaan akal dan budi. (Soehoet, 2003)

Penulis mengambil definisi tersebut karena dalam hal ini komunitas yang dijadikan sebuah organisasi dan pola komunikasi antar anggota maupun leader menggunakan bahasa verbal ataupun nonverbal.

Selain komunikasi verbal adapun pola komunikasi nonverbal melalui media sosial, Sampai saat ini media yang digunakan dalam berkomunikasi yaitu group chat dari aplikasi LINE. Peran seorang leader atau founder disini untuk menjaga pola berkomunikasi para anggota dari mulai kata-kata kasar, hingga pembahasan di luar konteks fotografi urban (out of topic). Maka dari itu seorang leader harus memiliki pola komunikasi yang baik terhadap setiap anggota nya.

Selain aplikasi LINE dalam media komunikasi, komunitas ini juga memanfaatkan aplikasi Instagram untuk memposting hasil foto yang dibuat oleh para anggota nya untuk mempopulerkan komunitas ini ke mata dunia. Maka dari itu Selain pola komunikasi yang baik, diharapkan seorang leader juga aktif dalam sebuah komunitas. Yakni aktif dalam menjalin hubungan dengan komunitas lain yang menggeluti bidang fotografi , aktif menseleksi fotofoto yang berkualiats dari anggotanya untuk di upload ke media sosial.

Menurut R. Wayne Pace dalam bukunya komunikasi organisasi menyebutkan bahwa organisasi sosial yaitu merujuk kepada pola-pola interaksi sosial (frekwensi dan lamanya kontak antara orangorang;kecenderungan mengawali kontak; arah pengaruh antara orang-orang; derajat kerjasama; perasaan tertarik, hormat, dan permusuhan; dan perbedaan status) dan regularitas yang teramati dan perilaku sosial orang-orang yang disebabkan oleh situasi sodial mereka alih-alih oleh karakteristik fisiologi atau psikologis mereka sebagai individu. ((Pace, R. Wayne \& Don, 2005))

Adanya pola atau regularitas dalam interaksi sosial mengisyaratkan bahwa adanya hubungan antara orang-orang yang mentransformasikan mereka dari suatu kumpulan individu menjadi sekelompok orang atau dari sejumlah kelompok menjadi suatu system yang besar.

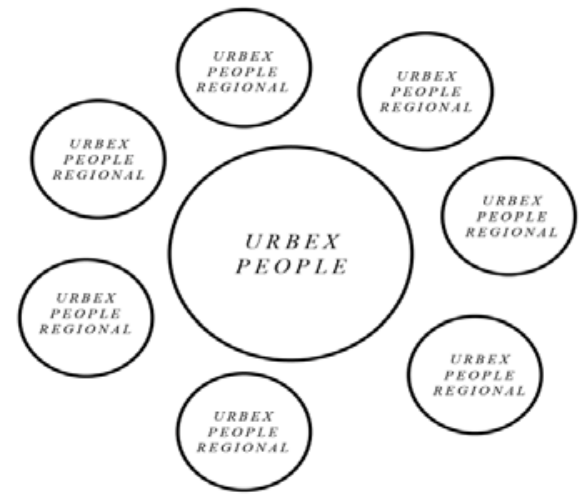

Gambar 1 Pola terpusat komunitas urbex people

Hubungan juga berkembang antara kelompokkelompok dan menghasilkan aspek status sosial yang berbeda. Status kelompok dalam system sosial yang yang lebih besar menjadi bagian status angotaanggota nya. Pola komunikasi yang terjadi antar leader dan member dalam komunitas urbex people bekasi yaitu pola komunikasi public yang definisinya menurut Dr. Arni Muhammad dalam bukunya komunikasi organisasi yaitu pertukaran pesan dengan sejumlah orang yang berada dalam organisasi atau yang diluar organisasi, secara tatap muka atau melalui media. Dan penulis menemukan fenomena komunikasi yang berlangsung melalu media chat Line. Dalam media chat Line di buat grup chat urbex people bekasi yang bertujuan sebagai media komunikasi leader dan antar member secara langsung tanpa ada yang ditutup-tutupi.

Selain pola komunikasi public, komunikasi yang berlangsung dalam komunitas ini adalah komunikasi interpersonal. Menurut Dr. Arni Muhammad komunikasi interpersonal yaitu proses pertukaran informasi di antara seseorang dengan paling kurang seorang lainya atau biasanya diantara dua orang 
yang dapat langsung diketahui balikanya.dengan bertambahnya orang yang terlibat dalam komunikasi, menjadi bertambahlah persepsi orang dalam kejadian komunikasi sehingga bertambah komplekslah komunikasi tersebut. (Muhammad, 2009). Pola komunikasi interpersonal ini dibutuhkan ketika ada suatu masalah serius antara leader dan member agar member lainya tidak ikut bicara dalam masalah tersebut. Agar masalah yang terjadi bisa terselesaikan secara intim tanpa campu tangan member lain.

Carl Jung (2016) mengembang suatu system tipe karakter berdasarkan dua sikap dan empat fungsi. Kedua sikap ini adalah introversi dan ekstroversi.'namun kini setiap orang sepakat bahwa dikotomi ini (introversi versus ekstroversi) tidak berguna lagi sebagai system tipe karakter yang bermanfaat. ((Jung, 2016))

Keempat fungsi tersebut adalah pikiran, perasaan, penginderaan dan intuisi. Fungsi pikiran berkenaan dengan gagasan. Melalui pikiran, manusia mencoba memahami sifat dunia dan dirinya. Perasaan adalah fungsi penilaian. Perasaan memberi nilai pada sesuatu dan memegang peranan dalam hal yang berkenaan dengan pengalaman senang dan sakit, marah, takut, sedih, bahagia, cinta, dll. Perabaan adalah fungsi yang berhubungan dengan persepsi atau fungsi realitas dan mengungkapkan fakta dan informasi konkret mengenai dunia. Intuisi menyatakan perolehan pengetahuan pengetahuan dan pemahaman aifat esensi dunia melalui pengalaman mistis dan dari sumber-sumber yang tidak disadari.

Variable lepas dalam penelitian ini yaitu loyalitas member dalam komunita urbex people bekasi. Definisi loyalitas yang diuangkapkan oleh Utomo (Tommy dkk.,2010) Loyalitas dapat dikatakan sebagai kesetiaan seseorang terhadap suatu hal yang bukan hanya berupa kesetiaan fisik semata, namun lebih pada kesetiaan non fisik seperti pikiran dan perhatian. Loyalitas para karyawan dalam suatu organisasi itu mutlak diperlukan demi kesuksesan organisasi itu sendiri. Menurut Reichheld, semakin tinggi loyalitas para karyawan di suatu organisasi,maka semakin mudah bagi organisasi itu untuk mencapai tujuan-tujuan organisasi yang telah ditetapkan sebelumnya oleh pemilik organisasi. Begitu pula sebaliknya, bagi organisasi yang loyalitas para karyawannya rendah, maka semakin sulit bagi organisasi tersebut untuk mencapai tujuantujuan organisasinya yang telah ditetapkan sebelumnya oleh para pemilik organisasi.

Pengertian Kepemimpinan Menurut Maxwell, Kepemimpinan adalah pengaruh tidak lebih yakni kemampuan memperoleh pengikut. Maxwell menyimpulkan bahwa setiap orang masing-masing mempengaruhi dan dipengaruhi orang lain. Itu berarti bahwa semua orang memimpin dalam beberapa bidang, sementara dalam bidang lain seseorang dipimpin. ((maxwell, 2009))

Jadi bila seseorang tidak dapat mempengaruhi orang lain, maka orang lain tidak mengikutinya. Bila orang lain tidak mengikutinya berarti orang tersebut bukanlah seorang pemimpin.

Menurut Maxwell kepemimpinan itu berkembang setiap hari. Kemampuan memimpin bukan hanya suatu bakat sejak lahir, tetapi sesungguhnya merupakan kumpulan dari berbagai ketrampilan, yang hampir seluruhnya dapat dipelajari serta ditingkatkan. Namun diperlukan suatu proses yang tidak terjadi hanya dalam semalam, karena aspek kepemimpinan sangat banyak : kehormatan, pengalaman, kekuatan, emosional, ketrampilan membina hubungan dengan sesama, disiplin, visi, dan sebagainya. Maxwell mengatakan bahwa pemimpin yang sukses adalah orang yang belajar, dimana proses belajarnya berkelanjutan, sebagai hasil dari disiplin pribadi dan ketekunan. Jadi kepemimpinan berjalan dari hari ke hari dimana sasaran setiap harinya haruslah menjadi sedikit lebih baik atau membangun di atas kemajuan hari sebelumnya ((maxwell, 2009)).

\section{METODOLOGI PENELITIAN}

Metode yang digunakan penulis dalam penelitian ini adalah metode kualitatif. Menurut Creswell (2009: 292) tujuan dari metode kualitatif adalah memahami situasi, peristiwa, kelompok, atau interaksi sosial tertentu yang bermaksud sebagai proses investigasi bagi peneliti secara perlahan-lahan memaknai suatu fenomena sosial dengan membedakan, membandingkan, menggandakan, mengkatalogkan, dan mengklasifikasikan objek penelitian. mengkatalogkan, dan mengklasifikasikan objek penelitian. ((Creswell, n.d.))

Dalam mengembangkan penelitian lebih lanjut penulis menggunakan pendekatan fenomenologi. Menurut John W. Cresswell dalam bukunya research design pendekatan kualitatif, kuantitatif dan mixed, fenomenologi merupakan strategi penelitian dimana di dalam nya peneliti mengidentifikasi hakikat pengalaman manusia tentang suatu fenomena tertentu. Memahami pengalaman-pengalaman hidup manusia menjadikan filsafat fenomenologi sebagai suatu metode penelitian yang rposedur-prosedurnya mengharuskan peneliti untuk mengkaji sejumlah subjek dengan terlibat secara langsung dan relative lama di dalam nya untuk mengembangkan pola-pola dan relasi-relasi makna (Moustakas, 1994). Dalam proses ini, meneliti mengesampingkan terlebih dahulu pengalaman-pengalaman partisipan yang ia teliti (Nieswiadomy,1993).

Pengumpulan data dilakukan dengan cara ikut 
berpartisipasi dalam komunitas urbex people bekasi, penulis menganalisa pola komunikasi yang terjadi antara leader dengan anggota nya melalu grup chat Line. Dan menemukan leader urbex people bekasi belum mampu berkomunikasi dengan baik kepada naggota nya karena apa yang di inginkan anggota nya leader aktif berinteraksi dalam grup chat Line.

\section{HASIL DAN PEMBAHASAN}

Ubex People adalah sebuah komunitas sosial yang didirikan oleh seorang bernama dhery pada tanggal 25 september 2014. Pria ini membentuk satu komunitas urbex people dengan tujuan awal mengumpulkan orang-orang yang memiliki hobi fotografi. Berbagi pengalaman, berbagi hasil foto dan berbagi hal lain di dunia fotografi.

People regional bekasi, kemunitas ini berdiri pada tanggal 24 september 2015, didirikan oleh reynold, salah satu mahasiswa perguruan tinggi swasta di Jakarta, awalnya reynold menyukai hal fotografi yang sifat nya "urban". Foto-foto ekstrim menggunakan api, asap dan bertopeng serta dengan latar belakang foto Gedung-gedung tua atau bangunan tua. Sampai suatu saat ia mencoba membuat satu komunitas yang menjadi bagian dari urbex people. Seiring berjalan nya waktu, banyak member yang ikut bergabung dalam komunitas ini.

Struktur yang terjalin dalam komunitas ini yakni pola kepemimpinan terpusat, dimana dalam komunitas ini memiliki satu pemimpin yang sifat nya official atau pemimpin pusat, seiring berjalan nya waktu munculah sporadis di setiap wilayah membentuk komunitas Urbex People regional yang dipimpin oleh pemimpin dari masing-masing wilayah. Pada akhirnya pemimpin pusat membuat group chat di aplikasi LINE untuk mempermudah memberikan informasi ke masing-masing wilayah regional mengenai event, pembuatan kaos, atau bahkan bakti social.

Khusus untuk komunitas Urbex People regional bekasi ini, yang Sampai akhirnya membuat satu event urban fotografi di wilayah harapan indah , Bekasi. Karena ada nya event tersebut, yang awal nya jumlah member hanya 23 orang, seriring berjalan nya waktu jumlah member semakin banyak mencapai 50-an orang. Dengan adanya satu masalah pola komunikasi dan tingkat keaktifan reynold sebagai leader maka para member banyak yang mengeluh, bahkan ada beberapa member yang belum tau siapa leader urbex people bekasi. Masalah tersebut dikarenakan seorang leader tidak dapat melakukan komunikasi yang baik terhadap para anggotanya. Leader pun jarang aktif di group LINE untuk diskusi event yang akan berlangsung, bahkan ketika event urbexmeet 2 di pekayon bulan lalu, seorang leader tidak berperan aktif dalam acara tersebut, sehingga bnyak para member yang merasa tidak diperhatikan oleh leader. Dan untungnya salah satu dari member urbex bekasi bernama Killa dapat mengkoordinir event tersebut secara keseluruhan di bantu dengan member-member lain agar event tersebut berjalan dengan lancer. Setelah event urbexmeet tersebut, banyak member mengeluh dan jumlah member menurun, karena bnyak yang merasa komunitas ini kurang aktif dikarenakan reynold sebagai leader tidak memberikan pengaruh yang baik terhadap membernya. Dalam hal ini karakter dari seorang pemimpin mempengaruhi pola komunikasi terhadap anggota nya. Secara tidak langsung dari permasalahan di atas, Reynold sebagai pemimpin memiliki karakter yang introvert yaitu jarang sekali berkomunikasi dengan anggota nya yang menyebabkan banyak miss communication dalam hal yang berkaitan dengan komunitas ini.

Pada akhirnya beberapa member berdiskusi dan sepakat untuk mengganti seorang leader nya. Hasil diskusi di pantau oleh perwakilan dari urbex people pusat untuk menengahi permasalahan leader di komunitas urbex people bekasi.

Dengan seorang pemimpin yang baru di komunitas ini, dan kebetulan penulis juga ikut terlibat dalam komunitas ini, maka seiring berjalan nya waktu komunitas urbex people Bekasi bias dikatakan maju pesat dikarenakan pola komunikasi seorang leader yang baru cukup baik, dalam pengkarakteran yang ditulis oleh Carl Jung, pemimpin yang baru ini memiliki karakter ekstrovert, lebih terbuka terhadap anggota nya sehingga chat group LINE juga selalu ramai, selalu ada bahan yang di diskusikan seperti event, tehnik foto, tehnik editing foto, bahkan ada beberapa produk endorsement lokal Bekasi mengajukan kerjasama kepada komunitas urbex people Bekasi. Hal ini membuat para anggota menjadi lebih loyal untuk memajukan komunitas ini.

\section{Pola komunikasi Leader Urbex people Bekasi}

Setelah menganalisa fenomena yang ada dilapangan, penulis dapat menggambarkan pola komunikasi dalam komunitas ini. Penulis cara ikut berpartisipasi dalam komunitas urbex people bekasi, penulis menganalisa pola komunikasi yang terjadi antara leader dengan anggota nya melalui grup chat Line. Dan penulis menemukan leader urbex people bekasi belum mampu berkomunikasi dengan baik kepada naggota nya, karena keinginan dari anggota, seorang leader selalu aktif berinteraksi dalam grup chat Line untuk memberikan informasi yang bermanfaat seputar fotografi atau merangkul anggota nya untuk membuat suatu event fotografi. Para member menganggap seorang leader hanya member yang pasif, tidak bisa berbaur dengan yang lainya.

Permasalahan lainya dipacu karena seorang leader jarang menghimpun anggota nya untuk hunting foto. Karena sebuah komunitas foto akan mati jika tanpa karya. Karya fotografi tersebut yang buat komunitas ini di kenal masyarakat. Sikap pasif seorang leader ini menimbulkan keresahan sebagian besar komunitas ini, sehingga sebagian member tersebut keluar dari komunitas ini. Ada sebagian member yang bertahan 
karena mempertahankan hoby nya dalam bidang fotografi. Hingga pada akhirnya beberapa member yang bertahan ini menginginkan untuk adanya perubahan, yaitu penggantian seorang leader yang baru. Dalam hal ini harus ada persetujuan dari komunitas urbex people pusat yang telah disebutkan di atas.

Loyalitas anggota juga sangat penting dalam komunitas urbex people bekasi, karena dengan banyak nya jumlah anggota, maka tujuan dari komunitas ini tercapai yakni, mengumpulkan orangorang yang hoby fotografi khusus nya street photography. hal ini sangat dipengaruhi oleh dua variable terikat yang sebelumnya telah dibahas, yaitu pola komunikasi seorang leader dan tingkat keaktifan leader komunitas ini. Ketika leader tidak dapat berkomunikasi dengan baik, maka banyak anggota komunitas ini keluar dari komunitas, begitupun terhadap tingkat keaktifan seorang leader, jika leader kurang aktif dalam komunitas, maka yang terjadi komunitas ini seolah tidak memiliki arah.

\section{KESIMPULAN}

Dari hasil penelitian di atas penulis dapat mentimpulkan bahwa :

1. Pola komunikasi seorang leader sangat berpengaruh positif terhadap loyalitas member komunitas urbex people bekasi.

2. Tingkat keaktifan seorang leader sangat dibutuhkan , agar para member nya tetap loyal terhadap komunitas urbex people bekasi. Terlihat dari beberapa kasus yang telah dijelaskan di bab pembahasan apabila seorang pemimpin pasif maka akan berpengaruh negatif terhadap anggota nya, begitu sebaliknya, apabila seorang pemimpin aktif maka akan memberikan pengaruh yang positif untuk anggota nya.

3. pola komunikasi dan tingkan keaktifan leader berpengaruh simultan terhadap loyalitas member. Bisa dikatakan jumlah member sangat dipengaruhi oleh pola komunikasi dan tingkat keaktifan leader itu sendiri

\section{REFERENSI}

Creswell, J. (n.d.). Research Design: Qualitative, Quantitative, and Mixed Methods Approaches. SAGE: Social Science.

Jung, C. (2016). Psychological Types. Martino Fine Books.

maxwell, J. C. (2009). Developing The Leaders Around You. Jakarta: Erlangga.

Muhammad, A. (2009). Komunikasi Organisasi. Jakarta: PT Bumi Aksara. Jakarta: Bumi aksara. https://doi.org/10.1007/s00134-0031920-y

Muhammad, D. (n.d.). Arni. 2004 Komunikasi Organisasi. Jakarta: Bumi Aksara.

Pace, R. Wayne \& Don, F. F. (2005). Teori Komunikasi. bandung: Rosdakarya.

Soehoet, H. (2003). dasar dasar jurnalistik.

\section{PROFILE PENULIS}

Faqihar Risyan, S. Ikom, MM, lahir di Jakarta tanggal 23 Juli 1987. Penulis bekerja di bidang pendidikan, yakni mengajar di salah satu perguruan tinggi swasta, Universitas Bina Sarana Informatika dengan program studi penyiaran. Sudah berkarir hampir 9 tahun menjadi dosen di perguruan tinggi Universitas Bina Sarana Informatika. Di luar mengajar, penulis juga bergerak dalam pembuatan tayangan audio visual seperti iklan, film, program televise, khusus nya dalam pengoperasian kamera dan drone. 